\title{
Contemporary Trends in Oral Antiplatelet Agent Use in Patients Treated with Percutaneous Coronary Intervention for Acute Coronary Syndrome
}

\author{
Kibum Kim, PhD; Todd A. Lee, PharmD, PhD; Daniel R. Touchette, PharmD, MA, FCCP; \\ Robert J. DiDomenico, PharmD, BCPS, FCCP; Amer K. Ardati, MD; and Surrey M. Walton, PhD
}

\begin{abstract}
BACKGROUND: Recent trials demonstrated the efficacy of prasugrel and ticagrelor compared with clopidogrel in the reduction of cardiovascular complications in patients with acute coronary syndrome (ACS). However, it is unclear how use of the 3 antiplatelet medications has changed in commercially insured patients since the advent of the new agents.

OBJECTIVES: To (a) describe the adoption of prasugrel and ticagrelor in patients who received percutaneous coronary intervention (PCI) for the onset of ACS and (b) explore patient factors associated with the selection of the drug to provide insight into utilization patterns of these antiplatelet agents.

METHODS: Patients who received a new dispensing of an antiplatelet agent following a hospitalization for a $\mathrm{PCI}$ administered for ACS were identified from insurance claims between 2009 and 2013. Demographics and comorbid conditions were determined based on a 6 -month period before the ACS event. Longitudinal trends in antiplatelet agent selection were illustrated using descriptive statistics segmented by month and quarter. Using logistic regressions with stepwise model selection, factors associated with use of the newer medications, as well as with the selection between ticagrelor and prasugrel, were identified.
\end{abstract}

RESULTS: The analysis included 66,335 subjects. The use of clopidogrel decreased from $100 \%$ to roughly $65 \%$ of total antiplatelet agent use by the end of 2011 and leveled off thereafter. The introduction of ticagrelor in 2011 coincided with a drop in prasugrel initiation from 35\%-18\% by December 2013. The use of new agents as opposed to use of clopidogrel was associated with younger age ( $<65$ years), male gender, and a diagnosis of ST-elevation myocardial infarction. In addition, conditions increasing mortality and risk of cardiovascular complication were associated with higher odds of using clopidogrel. The odds of using ticagrelor over prasugrel increased with older age and history of a cerebrovascular event.

CONCLUSIONS: In 2013, clopidogrel remained the most prescribed agent. Meanwhile, ticagrelor had gradually replaced a substantial portion of prasugrel initiation. Further investigation into outcomes associated with the newer agents, as well as reasons behind the conservative use of the antiplatelet agents, is warranted.

J Manag Care Spec Pharm. 2017;23(1):57-63

Copyright $\odot 2017$, Academy of Managed Care Pharmacy. All rights reserved.

\section{What is already known about this subject}

Prasugrel and ticagrelor reduce cardiovascular complications in patients with acute coronary syndrome (ACS).

Among patients receiving antiplatelet agents in hospitals registered in the National Cardiovascular Data Registry, the proportion of patients using prasugrel increased from 3\% in October 2009 to $18 \%$ in September 2012, with a corresponding decrease in the use of clopidogrel use.

\section{What this study adds}

As of 2013, clopidogrel continued to be a major option in ACS-percutaneous coronary intervention (PCI) patients, and a substantial portion of prasugrel initiation had been replaced by ticagrelor. This trend could not be fully explained by the efficacy profiles of the 3 antiplatelet agents.

Clinical practice preferred clopidogrel to the newer agents even in patients having risk factors of further myocardial infarction or other complications

A sizable number of patients using the newer antiplatelet agents had a history of labeled conditions with increased risk of cardiovascular complications in which use of those agents are recommended to be avoided.

A cute coronary syndrome (ACS) imposes a major burden on the U.S. health care system. There were 1.14 million hospitalizations for ACS in 2010, and the annual medical cost for each commercially insured case ranged between $\$ 34,000$ and $\$ 87,000$, depending on the initial treatment. ${ }^{1,2}$ Surgical intervention is important to reduce cardiovascular complications. ${ }^{2-5}$ Further, across the wide spectrum of ACS care options, the use of antiplatelet therapy along with aspirin administration, referred to as dual antiplatelet therapy, is a key recommendation in the prevention of secondary events. ${ }^{3,5}$

Antiplatelet management in ACS care has progressed substantially over the last 2 decades. In 1997, the U.S. Food and Drug Administration approved clopidogrel for the secondary prevention of cardiovascular events, and it experienced continuous growth in use. ${ }^{6-10}$ Recently, ACS care evolved with approvals of third-generation oral antiplatelet therapies that 
included prasugel and ticagrelor, which are commonly indicated as an adjunct to percutaneous coronary intervention (PCI) for a diagnosis of ACS. ${ }^{11,12}$ In randomized trials, prasugrel and ticagrelor reduced the risk of the composite endpoint of myocardial infarction, stroke, and cardiovascular death in comparison with clopidogrel. ${ }^{13,14}$ Further, using prasugrel or ticagrelor was cost-effective in comparison with the historic gold standard. ${ }^{15,16}$ Corresponding to all the evidence, clinical guidelines were updated with recommendations on using the recently approved agents. $3,5,17-19$

A recent study involving the National Cardiovascular Data Registry showed that the proportion of patients using prasugrel increased from 3\% in October 2009 to 18\% in September 2012 in patients with ST-elevation myocardial infarction (STEMI) or non-ST-elevation myocardial infarction (NSTEMI). ${ }^{20}$ However, because ticagrelor was not included in this study, it is unclear how the availability of the third agent affected the choice of antiplatelet agents. In addition, the results from the National Cardiovascular Data Registry may not be generalizable to national practice, since being enrolled in the program is voluntary, which makes it more likely to reflect clinical practices that would adhere to guidelines. ${ }^{20}$

The objective of this analysis was to describe trends in the use of 3 oral antiplatelet agents in commercially insured ACS patients who have newly received PCI.

\section{Methods}

\section{Data Sources}

Paid claims for a commercially insured population were obtained from Truven Health Analytics. The MarketScan Research Databases include de-identified patient-level medical and pharmacy claims for approximately 130 million subjects enrolled between the beginning of 2009 and the end of 2013 . The research was deemed exempt by a local institutional review board.

\section{Study Design and Analytic Cohort}

A time-series analysis was performed for the patients who initiated 1 of the oral antiplatelet agents for post ACS-PCI care. Patients who were discharged from a hospitalization with a primary diagnosis of ACS (International Classification of Diseases, Ninth Revision, Clinical Modification [ICD-9-CM] codes 410.xx [except 410.x2], 411.1x, and 411.8x) between July 2009 and December 2013 were identified, and their PCI procedures during hospitalization were determined using ICD-9-CM codes and Current Procedural Terminology codes. Of the ACS-PCI subjects, patients who initiated clopidogrel, prasugrel, or ticagrelor within 14 days from the date of discharge were included in the analytic cohort. In order to avoid misinterpretation of the intended switching between loading and maintenance uses, the analytic cohort excluded patients who received 2 or more different antiplatelet agents during the 14-day assessment period. To focus on new users, patients were excluded who had received any antiplatelet medication during the 6 months before the ACS-PCI admission. ${ }^{21-23}$ Over the same baseline period, medical history that potentially influenced the selection of an antiplatelet agent was collected using ICD-9-CM codes. ${ }^{24-28}$ For example, a past diagnosis of cerebrovascular encounter needs to be assessed before determining the medication strategy., ${ }^{3,5,6,11,12}$ Underlying myocardial infarction and other key comorbidities were also collected using a known coding algorithm for defining Charlson comorbidities. ${ }^{29}$

\section{Statistical Approach}

Descriptive statistics segmented by calendar time were used to summarize the use of the 3 medications. The primary variable used in describing trends in new medication adoption was the monthly number and proportion of patients who newly initiated 1 of the oral antiplatelet agents. In addition to the proportions, the $95 \%$ confidence intervals (CIs) of the changes in the proportions were projected using a standard bootstrap resampling percentile approach with 1,000 replicates.

In order to provide additional insight into the use of these drugs, differences in patient characteristics across the 3 drug groups were compared. Age distributions were compared between clopidogrel and third-generation agent patients with a Student t-test and compared across the 3 groups using analysis of variance. Categorical variables were summarized using percentiles and $\chi^{2}$ tests. Using frequency statistics, drug use was also looked at in patients with labeled contraindications, such as prasugrel use in patients with a history of transient ischemic attack (TIA), prasugrel in patients aged over 75 years without further risk factors of cardiovascular complication, or ticagrelor use in patients with a history of cerebrovascular hemorrhage. ${ }^{11,12}$

Predictors in the selection between third-generation agents versus clopidogrel and between ticagrelor versus prasugrel were examined using logistic regression model adjusted for the semiannually segmented period and geographic location. Patient factors for consideration in the regression model were selected from the baseline characteristics whose $P$ value in a bivariate analysis was less than 0.1. Independent variable selection was then performed using a stepwise forward selection approach with significance levels for entering effects of 0.1 and for the removing effect of 0.05. All of the statistical analysis was performed using SAS software version 9.3 (SAS Institute, Cary, NC).

\section{Results}

A total of 66,335 antiplatelet agent initiations over the 4.5-year period were identified. Of these, 33,307 initiated treatment between July 2009 and June 2011, the study period before ticagrelor was approved, and $85 \%$ of those cases were clopidogrel users. From July 2011 to the end of 2013, 68\%, 25\%, 


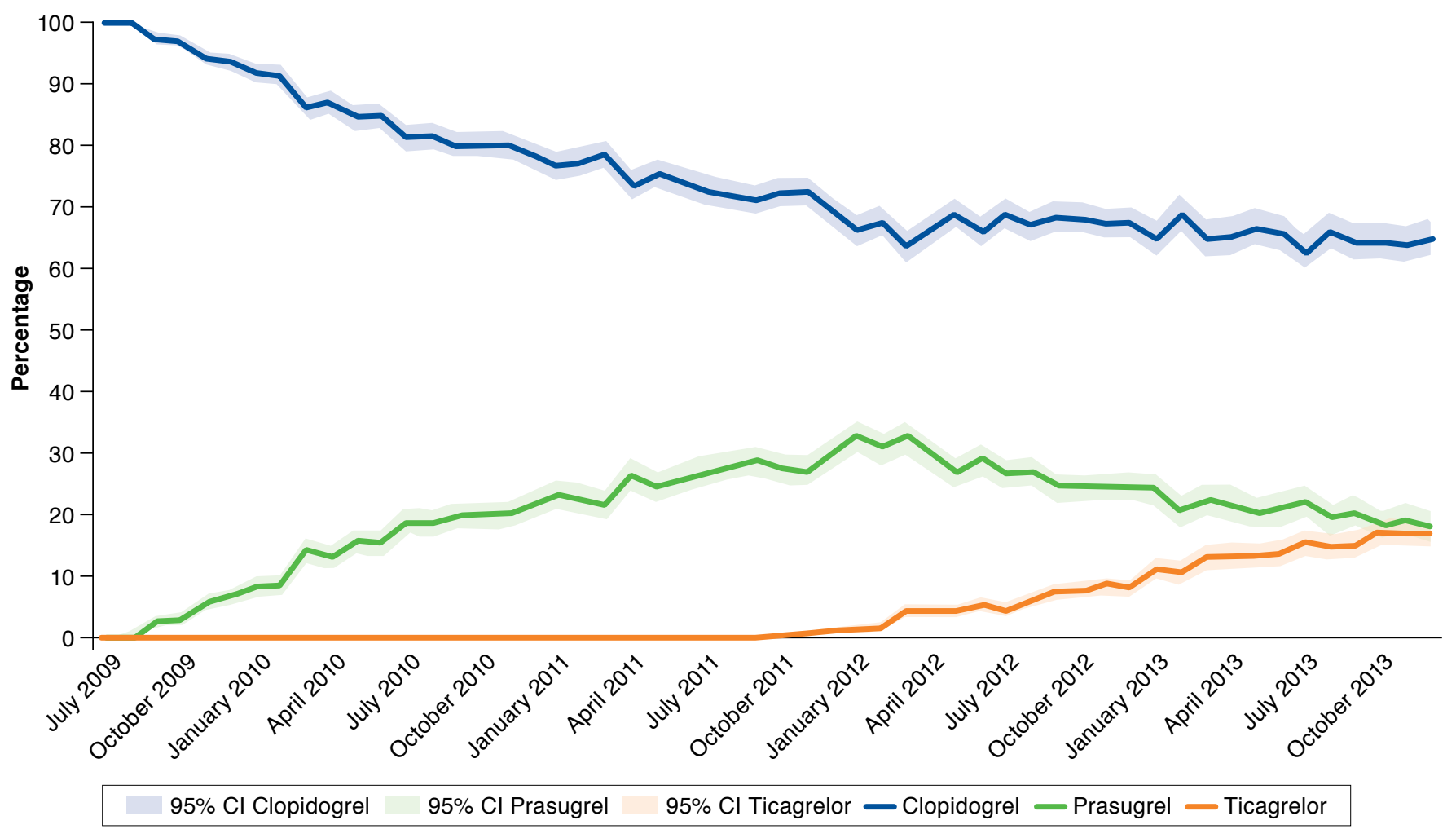

CI=confidence interval.

and $7 \%$ of the overall cohort were clopidogrel, prasugrel, and ticagrelor initiators, respectively (Appendix A, available in online article).

After prasugrel was approved, the proportion of prasugrel users increased by an average of 1 percentage point per month through March 2012, when the proportion plateaued. A decrease in the proportion of clopidogrel initiators had continued up to this point, but the proportion of clopidogrel use was essentially constant thereafter. Meanwhile, the use of ticagrelor increased by an average of 0.6 percentage points per month beginning March 2012 and reached 17\% of the antiplatelet agent use at the end of 2013, which coincided with a decline in the proportion of prasugrel use. The bootstrapped CIs of prasugrel and ticagrelor uses overlapped each other after October 2013, but those intervals did not overlap with the range of the clopidogrel use (Figure 1). When the trends were stratified by diagnosis, proportions of the new agents increased faster in the STEMI group, with $20 \%$ and $19 \%$ of the STEMI subjects at the last quarter of 2013 being prescribed with prasugrel and ticagrelor, compared with non-ST-segment elevation ACS patients who had respective proportions of $17 \%$ and $15 \%$ during the same quarter $(P<0.01)$. The recently approved antiplatelet agents were adopted faster in male patients and in those aged younger than 55 years (Appendix B, available in online article).

The average proportion of patients with a STEMI diagnosis was higher in those using prasugrel or ticagrelor than the percentage in the clopiodgrel group $(57.1 \%$ vs. $50.5 \%, P<0.01)$. When clopidogrel users were compared with third-generation agents, the proportions of patients having a history of a cardiovascular disorder, including MI (9.1\% vs. $8.2 \%)$, ischemic stroke ( $1.7 \%$ vs. $0.7 \%)$, intracerebrovascular bleedings $(0.16 \%$ vs. $0.07 \%$ ), and extracerebrovascular bleedings ( $7.0 \%$ vs. $5.5 \%)$, were significantly $(P<0.05)$ higher in patients treated with clopidogrel. Also, patients using newer agents were younger than the clopidogrel patients, with average ages of 56.3 years and 61.0 years, respectively $(P<0.001$; see Appendix A for more detail).

From the logistic regression approach, being male and having STEMI were associated with a higher likelihood of using a third-generation agent, with adjusted odds ratios (OR) of 1.32 (95\% CI $=1.26-1.39)$ and $1.28(95 \% \mathrm{CI}=1.23-1.32)$, respectively. Risk factors for further cardiovascular events, including age over 54 years $(\mathrm{OR}=0.86,95 \% \mathrm{CI}=0.83-0.90)$ and 64 years $(\mathrm{OR}=0.39,95 \% \mathrm{CI}=0.37-0.42)$; congestive heart failure 
TABLE 1 Factors Associated with Use of ThirdGeneration Antiplatelet Agents and Associated with Use of Ticagrelor

\begin{tabular}{|c|c|c|}
\hline Patient Factors & $\begin{array}{c}\text { Third-Generation } \\
\text { Agents vs. } \\
\text { Clopidogrel } \\
\text { OR (95\% CI) }\end{array}$ & $\begin{array}{c}\text { Ticagrelor vs. } \\
\text { Prasugrel } \\
\text { OR }(95 \% \text { CI })\end{array}$ \\
\hline Male & $1.32(1.26-1.39)$ & $0.76(0.68-0.85)$ \\
\hline Age (years): $55-64$ vs. $<55$ & $0.86(0.83-0.90)$ & $1.03(0.92-1.15)$ \\
\hline Age (years): $\geq 65$ vs. $<55$ & $0.39(0.37-0.42)$ & $1.55(1.35-1.77)$ \\
\hline STEMI vs. NSTE-ACS & $1.28(1.23-1.32)$ & - \\
\hline Cardiac disorder: CHF & $0.89(0.84-0.94)$ & - \\
\hline Cardiac disorder: underlying MI & $0.89(0.84-0.96)$ & - \\
\hline Risk of bleeding: ECH & $0.86(0.79-0.93)$ & - \\
\hline Risk of bleeding: ICH & $0.51(0.27-0.95)$ & $7.23(1.44-36.26)$ \\
\hline $\begin{array}{l}\text { Cerebrovascular event: } \\
\text { ischemic stroke }\end{array}$ & $0.47(0.38-0.57)$ & $1.70(1.03-2.79)$ \\
\hline Cerebrovascular event: TIA & $0.76(0.60-0.96)$ & - \\
\hline Renal disorders & $0.74(0.68-0.82)$ & - \\
\hline Substance abuse & $0.87(0.83-0.91)$ & $0.84(0.75-0.95)$ \\
\hline Pulmonary disorder & $0.86(0.81-0.91)$ & - \\
\hline Chronic liver disorders & $0.89(0.78-1.00)$ & - \\
\hline Diabetes & $1.05(1.00-1.09)$ & - \\
\hline Hemi or paraplegia & $0.69(0.45-1.06)$ & - \\
\hline Dyslipidemia & $1.07(1.03-1.12)$ & $0.90(0.81-0.99)$ \\
\hline Dementia & $0.46(0.28-0.76)$ & $2.78(0.87-8.91)$ \\
\hline Cancer & $0.84(0.77-0.93)$ & - \\
\hline Health plan: HMO vs. PPO & $0.83(0.78-0.88)$ & - \\
\hline Health plan: comprehensive vs. PPO & $0.98(0.91-1.05)$ & - \\
\hline Health plan: other vs. PPO & $0.99(0.94-1.04)$ & - \\
\hline
\end{tabular}

$C H F=$ congestive heart failure; $C I=$ confidence interval; $E C H=$ extra cerebrovascular hemorrhage; $\mathrm{HMO}=$ health maintenance organization; $\mathrm{ICH}=$ intracerebrovascular hemorrhage; $M I=$ myocardial infarction; NSTE-ACS = non-ST-segment elevation acute coronary syndrome; $O R=$ odds ratio; $P P O=$ preferred provider organization; STEMI =ST-segment elevation myocardial infarction; TIA = transient ischemic attack.

$(\mathrm{OR}=0.89,95 \% \mathrm{CI}=0.84-0.94)$; history of $\mathrm{MI}(\mathrm{OR}=0.89,95 \%$ $\mathrm{CI}=0.84-0.96)$; extra- and intracerebral bleedings ( $\mathrm{OR}=0.86$, 95\% CI=0.79-0.93 and $\mathrm{OR}=0.51,95 \% \mathrm{CI}=0.27-0.95)$; and ischemic cerebrovascular events such as stroke and TIA $(\mathrm{OR}=0.47,95 \% \mathrm{CI}=0.38-0.57$ and $\mathrm{OR}=0.76,95 \% \mathrm{CI}=0.60$ 0.96), were also associated with less use of third-generation agents. However, diabetes ( $\mathrm{OR}=1.05,95 \% \mathrm{CI}=1.00-1.09$ ) and dyslipidemia $(\mathrm{OR}=1.07,95 \% \mathrm{CI}=1.03-1.12)$ were positively related to the use of third-generation agents. When restricting the analysis to use of a third-generation drug, male gender $(\mathrm{OR}=0.76,95 \% \mathrm{CI}=0.68-0.85)$ was associated with less use of ticagrelor. On the other hand, underlying risk factors for cardiovascular complications, including ischemic stroke (OR=1.70, 95\% CI=1.03-2.79); cerebrovascular hemorrhage $(\mathrm{OR}=7.23,95 \% \mathrm{CI}=1.44-36.26)$; and age older than 64 years $(\mathrm{OR}=1.55,95 \% \mathrm{CI}=1.35-1.77)$, were associated with greater use of ticagrelor (Table 1).
The analysis identified a sizable number of subjects using the newer antiplatelet agents with a history of conditions in which use of those agents are recommended to be avoided. Of the 13,609 subjects starting prasugrel, 268 (1.97\%) were aged $\geq 75$ years. Of those, 167 ( $1.77 \%$ of the prasugrel patients) did not report a diagnosis of MI or diabetes over the baseline assessment period. The number of patients having a history of ischemic stroke or TIA were 1,643 , and 146 of those received prasugrel, which was also not a recommended use of the drug. With regard to the risk of bleeding, 12 of the prasugrel or ticagrelor users had a previous history of cerebrovascular hemorrhage.

\section{Discussion}

This study described broad trends of early antiplatelet agent use among commercially insured patients following PCI. While clopidogrel was used by the majority of the patients across the entire study period, an increase in the initiation of ticagrelor corresponded to a decrease in the use of prasugrel, resulting in the total percentage of patients starting the newer agents remaining constant. The results suggest a maximum loss of the clopidogrel market share beyond which the third-generation agents could not gain more.

Safety profiles of the novel agents that have to be considered potentially explain the use of clopidogrel by the majority of the ACS-PCI patients. Clinical trials demonstrated that prasugrel and ticagelor are more effective than clopidogrel in the reduction of the composite of MI, stroke, and cardiovascular death over the 12- to 15-month period after the onset of ACS. ${ }^{13,30}$ However, the key safety endpoint, major bleeding, of the study assessing the outcomes of prasugrel significantly favored clopidogrel. ${ }^{13}$ Although statistically insignificant, an increase in bleeding was also observed in the trials for ticagrelor versus clopidogrel. ${ }^{30}$ Potentially being associated with these riskbenefit profiles, guidelines added prasugrel and ticagrelor as an alternative to clopidogrel, but there was not an endorsement on one specific drug over the other. ${ }^{3,5,13,17,30}$ When this clinical evidence is taken into account, the adverse event profiles with the limited experience in the use of those newer agents likely outweighed the efficacy profiles in influencing clinical decisions.

Recent evaluations demonstrated that prasugrel and ticagrelor achieved an incremental cost per quality-adjusted life-years gain of less than $\$ 100,000$, and a genotype-guided therapy enabled the inclusion of the 2 new agents to be more cost-effective. ${ }^{31-33}$ However, whether the high cost of the newer agents is offset by better clinical outcomes has been underinvestigated in real-world populations. In this regard, the national average drug acquisition costs show that the acquisition cost of generic clopidogrel $75 \mathrm{mg}$ tablets was as low as $\$ 0.08$ per day, which was more than 100 times less than the daily cost of ticagrelor or prasugrel. ${ }^{34}$ Similarly, the cost of clopidogrel in previous economic evaluations was also 45 to 70 times lower than that of the newer agents. ${ }^{16,33}$ Whether this high medication cost is a 
barrier that cannot be paid off by better effectiveness needs to be investigated further.

Of the patients using a third-generation agent, ticagrelor gradually replaced prasugrel and reached $47 \%$ of the total third-generation antiplatelet agent use in December 2013. With the replacement of prasugrel with ticagrelor, contraindications in the use of prasugrel, such as older age and cerebrovascular events, acted as determinants. However, patients aged $\geq 75$ years were $11 \%$ of the total ticagrelor use, and those patients with a history of ischemic stroke or TIA accounted for only $2 \%$ of the total ticagrelor initiators, meaning that the replacement was not limited to conditions in which prasugrel was recommended to be avoided. Interestingly, running counter to these trends, studies using a hospital charge data master found that resource use over 30 to 90 days after ACS discharge decreased more with prasugrel, not ticagrelor. ${ }^{35,36}$ Whether drug use in the near future will echo the observational studies is another area for investigation.

Our research provides multiple stakeholders with useful information. For the parts of the pharmaceutical industry with interest in ACS care, this research provides general insight into how new agents permeated the U.S. antiplatelet agent market and what conditions were considered in antiplatelet agent selection. In addition to previous drug use studies, this analyses included the newest oral antiplatelet agents and covered an extended period during which multiple options competed with each other. ${ }^{10,20}$ The observed drug initiation pattern suggests a need for further study regarding factors that encouraged the use of clopidogrel.

\section{Limitations}

Any interpretation of the results of this analysis should take into account substantial limitations. First, the low price of the generic version of clopidogrel and other marketing strategies likely influenced treatment patterns, but these business-related aspects were beyond the scope of this analysis. Nevertheless, describing contemporary practice helps health care providers understand how use of the novel agents has changed and what patient factors played a key role in the selection of antiplatelet agents. Second, the data covered only a commercially insured population. Therefore, the results may not be generalizable to underinsured groups. However, considering that our results were quite similar to the longitudinal trends identified in the National Cardiovascular Data Registry from 2009 to 2012, it is likely that drug use in the general U.S. population did not largely differ from what this study demonstrated..$^{20}$ Finally, general disadvantages in the use of an administrative database, such as miscoded diagnoses or omitted information in filing claims could not be excluded from the analysis. For example, the specific diagnosis of ACS was determined on the basis of the ICD-9-CM algorithm that has been employed in multiple studies. ${ }^{36-38}$ However, there remains concern regarding the validity of this coding because insurance claims are designed for reimbursement purpose. Further, the data did not include full information regarding procedures provided during the index ACS-PCI admission, so some factors related to drug selection may not have been identified.

\section{Conclusions}

For PCI-treated ACS patients, especially those with a baseline risk of ACS complications, clopidogrel continued to be the most commonly used antiplatelet agent as of 2013. The uptake of ticagrelor in 2012 and 2013 encroached on about half of the prasugrel share. This replacement was associated with, but not limited to, patients having a history of cerebrovascular events. Use of the 3 antiplatelet agents did not fully correspond to the package labels and guideline recommendations, suggesting that future research should examine recommended use versus actual clinical practice.

\section{Authors}

KIBUM KIM, PhD, Pharmacotherapy Outcomes Research Center, and Department of Pathology, University of Utah, Salt Lake City. TODD A. LEE, PharmD, PhD; DANIEL R. TOUCHETTE, PharmD, MA, FCCP; and SURREY M. WALTON, PhD, Department of Pharmacy Systems, Outcomes and Policy, College of Pharmacy, and Center for Pharmacoepidemiology and Pharmacoeconomic Research, University of Illinois at Chicago. ROBERT J. DIDOMENICO, PharmD, BCPS, FCCP, Center for Pharmacoepidemiology and Pharmacoeconomic Research, and Department of Pharmacy Practice, College of Pharmacy, University of Illinois at Chicago. AMER K. ARDATI, MD, Division of Cardiology, College of Medicine, University of Illinois at Chicago.

AUTHOR CORRESPONDENCE: Surrey M. Walton, PhD, 833 S. Wood St., MC 871, Chicago, IL 60612. Tel.: 312.413.2775; Fax: 312.996.0868; E-mail: walton@uic.edu.

\section{DISCLOSURES}

No funding was received for the conduct of this study. DiDomenico received an honorarium from Amgen for the preparation of a heart failure drug monograph for Pharmacy Practice News and was a co-investigator on funded research for the Patient-Centered Outcomes Research Institute. DiDomenico also serves as an advisory board member for a heart failure program at Otsuka America Pharmaceuticals and as an advisory board member at Novartis Pharmaceuticals. Touchette has received unrestricted grant funding from Cardinal Health and Sunovion Pharmaceuticals and has also served as a consultant to and director of the American College of Clinical Pharmacy PracticeBased Research Network on a study funded by Pfizer. None of the authors of this study are involved in financial or personal relationships with agencies, institutions, or organizations that inappropriately influenced the statistical analysis plan or interpretation of the results.

Study concept and design were contributed by Kim, Lee, Touchette, and Walton, with assistance from DiDomenico and Ardati. Kim and Lee collected the data, and data interpretation was performed by Lee, DiDomenico, and Ardati, along with Kim and Walton and assisted by Touchette. The manuscript was written by Kim and Walton, with assistance from the other authors, and revised by Kim, Walton, and Lee, with assistance from the other authors. 


\section{REFERENCES}

1. Mozaffarian D, Benjamin EJ, Go AS, et al. Heart disease and stroke statistics-2016 update: a report from the American Heart Association. Circulation. 2015;133(4):e38-360

2. Zhao Z, Winget M. Economic burden of illness of acute coronary syndromes: medical and productivity costs. BMC Health Serv Res. 2011;11:35.

3. Amsterdam EA, Wenger NK, Brindis RG, et al. 2014 AHA/ACC guideline for the management of patients with non-ST-elevation acute coronary syndromes: executive summary: a report of the American College of Cardiology/ American Heart Association Task Force on Practice Guidelines. Circulation. 2014;130(25):2354-94

4. Levine GN, Bates ER, Blankenship JC, et al. 2015 ACC/AHA/SCAI focused update on primary percutaneous coronary intervention for patients with ST-elevation myocardial infarction: an update of the 2011 ACCF/AHA/SCAI Guideline for Percutaneous Coronary Intervention and the 2013 ACCF/AHA Guideline for the Management of ST-Elevation Myocardial Infarction: a report of the American College of Cardiology/ American Heart Association Task Force on Clinical Practice Guidelines and the Society for Cardiovascular Angiography and Interventions. Circulation. 2015;133(11):1135-47.

5. O'Gara PT, Kushner FG, Ascheim DD, et al. 2013 ACCF/AHA guideline for the management of ST-elevation myocardial infarction: a report of the American College of Cardiology Foundation/American Heart Association Task Force on Practice Guidelines. Circulation. 2013;127(4):e362-425.

6. PLAVIX (clopidogrel bisulfate) tablets. Bristol-Myers Squibb/Sanofi Pharmaceuticals Partnership. Revised July 2015. Available at: http://www. accessdata.fda.gov/drugsatfda_docs/label/2015/020839s061lbl.pdf. Accessed November 29, 2016

7. CAPRIE Steering Committee. A randomised, blinded, trial of clopidogrel versus aspirin in patients at risk of ischaemic events (CAPRIE). CAPRIE Steering Committee. Lancet. 1996;348(9038):1329-39.

8. Moussa I, Oetgen M, Roubin G, et al. Effectiveness of clopidogrel and aspirin versus ticlopidine and aspirin in preventing stent thrombosis after coronary stent implantation. Circulation. 1999;99(18):2364-66.

9. Debnath B, Al-Mawsawi LQ, Neamati N. Are we living in the end of the blockbuster drug era? Drug News Perspect. 2010;23(10):670-84.

10. Rao RV, Goodman SG, Yan RT, et al. Temporal trends and patterns of early clopidogrel use across the spectrum of acute coronary syndromes. Am Heart J. 2009;157(4):642-50.el.

11. EFFIENT (prasugrel) tablets, for oral use. Eli Lilly and Company. Revised July 2016. Available at: https://pi.lilly.com/us/effient.pdf. Accessed November 29, 2016.

12. BRILINTA (ticagrelor) tablets, for oral use. AstraZeneca. Revised September 2015. Available at: http://www.accessdata.fda.gov/drugsatfda_ docs/label/2015/022433s017lbl.pdf. Accessed November 29, 2016.

13. Wiviott SD, Braunwald E, McCabe $\mathrm{CH}$, et al. Prasugrel versus clopidogrel in patients with acute coronary syndromes. N Engl J Med. 2007;357(20):2001-15

14. Wallentin L, Becker RC, James SK, Harrington RA. The PLATO trial reveals further opportunities to improve outcomes in patients with acute coronary syndrome. Editorial on Serebruany. "Viewpoint: Paradoxical excess mortality in the PLATO trial should be independently verified" (Thromb Haemost 2011; 105.5). Thromb Haemost. 2011;105(5):760-62.

15. Mahoney EM, Wang K, Arnold SV, et al. Cost-effectiveness of prasugrel versus clopidogrel in patients with acute coronary syndromes and planned percutaneous coronary intervention: results from the trial to assess improvement in therapeutic outcomes by optimizing platelet inhibition with Prasugrel-Thrombolysis in Myocardial Infarction TRITON-TIMI 38. Circulation. 2010;121(1):71-79.

16. Cowper PA, Pan W, Anstrom KJ, et al. Economic analysis of ticagrelor therapy from a U.S. perspective: results from the PLATO study. J Am Coll Cardiol. 2015;65(5):465-76.
17. Cayla G, Silvain J, Collet JP, Montalescot G. Updates and current recommendations for the management of patients with non-ST-elevation acute coronary syndromes: what it means for clinical practice. Am J Cardiol. 2015;115(5 Suppl):10A-22A.

18. Kushner FG, Hand M, Smith SC, Jr, et al. 2009 focused updates: ACC/ AHA guidelines for the management of patients with ST-elevation myocardial infarction (updating the 2004 guideline and 2007 focused update) and ACC/AHA/SCAI guidelines on percutaneous coronary intervention (updating the 2005 guideline and 2007 focused update) a report of the American College of Cardiology Foundation/American Heart Association Task Force on Practice Guidelines. J Am Coll Cardiol. 2009;54(23):2205-41.

19. Wright RS, Anderson JL, Adams CD, et al. 2011 ACCF/AHA focused update of the guidelines for the management of patients with unstable angina/non-ST-elevation myocardial infarction (updating the 2007 guideline): a report of the American College of Cardiology Foundation/ American Heart Association Task Force on Practice Guidelines. Circulation. 2011;123(18):2022-60.

20. Sherwood MW, Wiviott SD, Peng SA, et al. Early clopidogrel versus prasugrel use among contemporary stemi and nstemi patients in the U.S. insights from the National Cardiovascular Data Registry. J Am Heart Assoc. 2014;3(2):e000849. Available at: https://www.ncbi.nlm.nih.gov/pmc/articles/ PMC4187510/. Accessed November 29, 2016.

21. Derek So; Ottawa Heart Institute Research Corporation. Transition from ticagrelor to clopidogrel following acute coronary syndrome: to bolus or not? ClinicalTrials.gov Identifier NCT02054663. Available at: https://clinicaltrials.gov/ct2/show/record/NCT02054663. Accessed November 29, 2016.

22. Angiolillo DJ, Saucedo JF, Deraad R, et al. Increased platelet inhibition after switching from maintenance clopidogrel to prasugrel in patients with acute coronary syndromes: results of the SWAP (SWitching Anti Platelet) study. J Am Heart Assoc. 2010;56(13):1017-23.

23. Payne CD, Li YG, Brandt JT, et al. Switching directly to prasugrel from clopidogrel results in greater inhibition of platelet aggregation in aspirintreated subjects. Platelets. 2008;19(4):275-81.

24. Andrade SE, Harrold LR, Tjia J, et al. A systematic review of validated methods for identifying cerebrovascular accident or transient ischemic attack using administrative data. Pharmacoepidemiol Drug Saf. 2012;21 (Suppl 1):100-28.

25. Jones SA, Gottesman RF, Shahar E, Wruck L, Rosamond WD. Validity of hospital discharge diagnosis codes for stroke: the Atherosclerosis Risk in Communities Study. Stroke. 2014;45(11):3219-25.

26. Berenson K, Casciano R, Makenbaeva D, Mozaffari E, Lamerato L, Corbelli J. Economic consequences of severe bleeding in patients with acute coronary syndrome in the USA. Adv Ther. 2010;27(8):564-79.

27. Chu SY, Merkler AE, Cheng NT, Kamel H. Readmission for infective endocarditis after ischemic stroke or transient ischemic attack. Neurohospitalist. 2015;5(2):55-58.

28. Arnold SV, Smolderen KG, Kennedy KF, et al. Risk factors for rehospitalization for acute coronary syndromes and unplanned revascularization following acute myocardial infarction. J Am Heart Assoc. 2015;4(2):pii: e001352 Available at: http://jaha.ahajournals.org/content/4/2/e001352.long. Accessed November 29, 2016

29. Quan H, Sundararajan V, Halfon P, et al. Coding algorithms for defining comorbidities in ICD-9-CM and ICD-10 administrative data. Med Care. 2005;43(11):1130-39

30. Wallentin L, Becker RC, Budaj A, et al. Ticagrelor versus clopidogrel in patients with acute coronary syndromes. N Engl J Med. 2009;361(11):1045-57.

31. Mauskopf JA, Graham JB, Bae JP, et al. Cost-effectiveness of prasugrel in a U.S. managed care population. J Med Econ. 2012;15(1):166-74.

32. Coleman CI, Limone BL. Cost-effectiveness of universal and platelet reactivity assay-driven antiplatelet therapy in acute coronary syndrome. Am J Cardiol. 2013;112(3):355-62. 
33. Patel V, Lin FJ, Ojo O, et al. Cost-utility analysis of genotype-guided antiplatelet therapy in patients with moderate-to-high risk acute coronary syndrome and planned percutaneous coronary intervention. Pharm Pract (Granada). 2014;12(3):438.

34. Centers for Medicare \& Medicaid Services. National average drug acquisition cost (NADAC). Available at: https://data.medicaid.gov/Drug-Prices/ NADAC-as-of-2016-05-04/f5xh-csvr. Accessed November 29, 2016.

35. Larmore C, Effron MB, Molife C, et al. "Real-world" comparison of prasugrel with ticagrelor in patients with acute coronary syndrome treated with percutaneous coronary intervention in the United States. Catheter Cardiovasc Interv. 2016;88(4):535-44.
36. Molife C, Frech-Tamas F, DeKoven M, et al. Comparison of healthcare resource utilization and costs in patients hospitalized for acute coronary syndrome managed with percutaneous coronary intervention and receiving prasugrel or ticagrelor. J Med Econ. 2015;18(11):898-908.

37. Bae JP, Faries DE, Ernst FR, et al. Real-world observations with prasugrel compared to clopidogrel in acute coronary syndrome patients treated with percutaneous coronary intervention in the United States. Curr Med Res Opin. 2014;30(11):2207-16

38. Simeone JC, Molife C, Marrett E, et al. One-year post-discharge resource utilization and treatment patterns of patients with acute coronary syndrome managed with percutaneous coronary intervention and treated with ticagrelor or prasugrel. Am J Cardiovasc Drugs. 2015;15(5):337-50. 
APPENDIX A Prevalence of Baseline Characteristics in the 3 Antiplatelet Agent User Groups

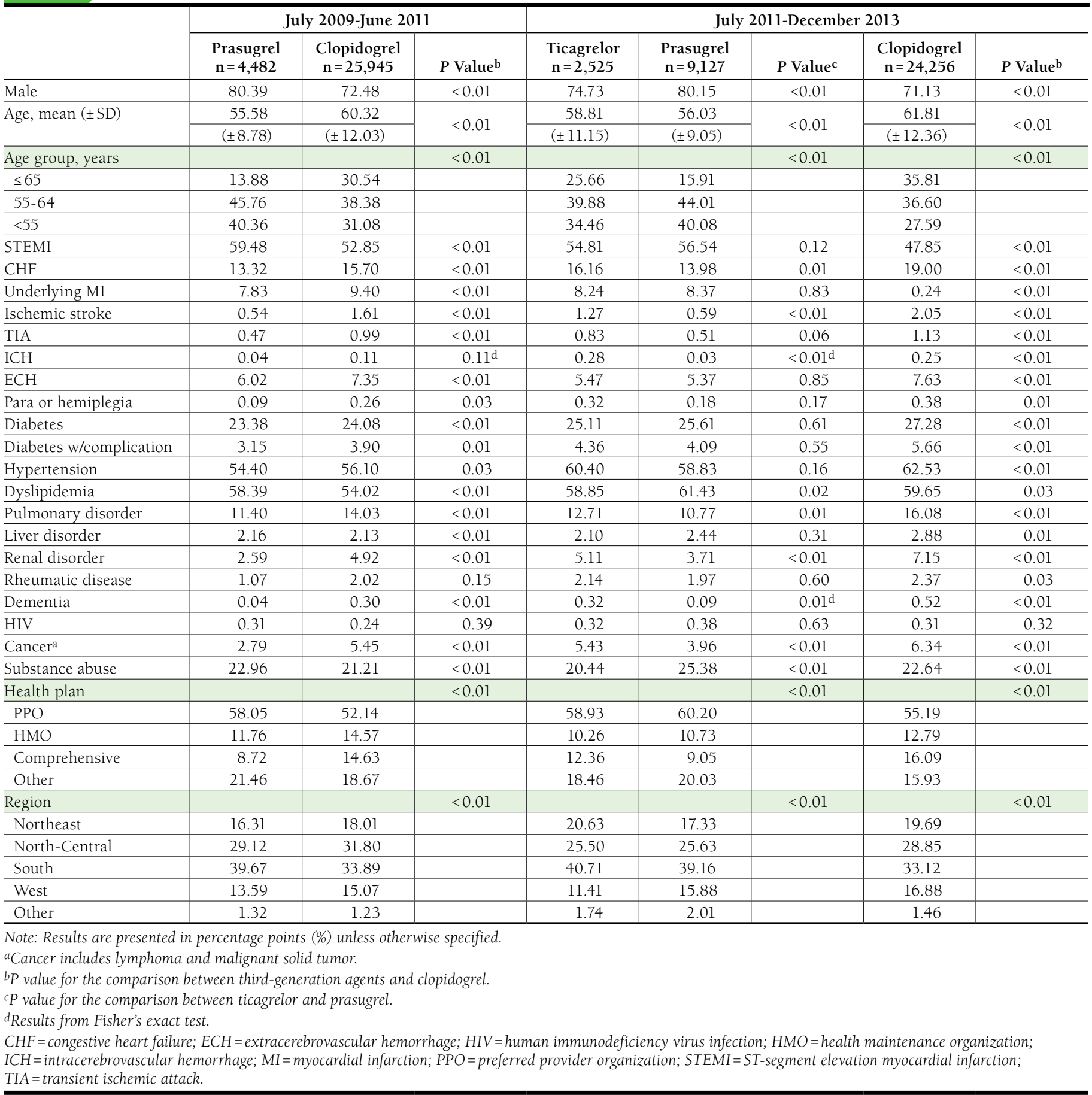


A. Trends by ACS Diagnosis Category

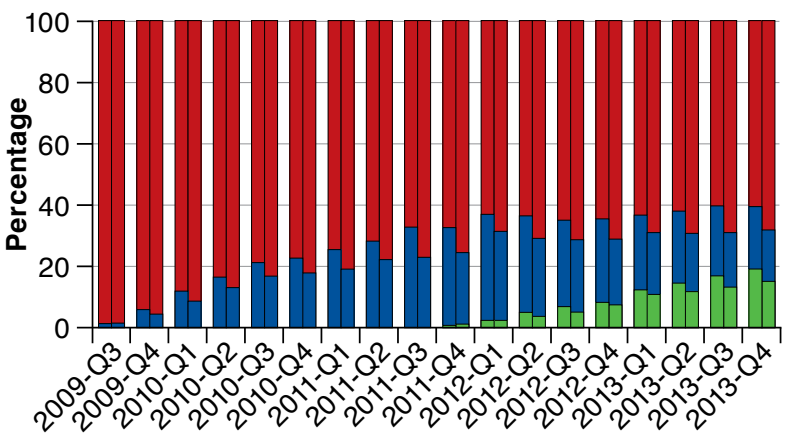

Note: Left colums: STEMI; right columns: NSTE-ACS.

C. Trends by Gender

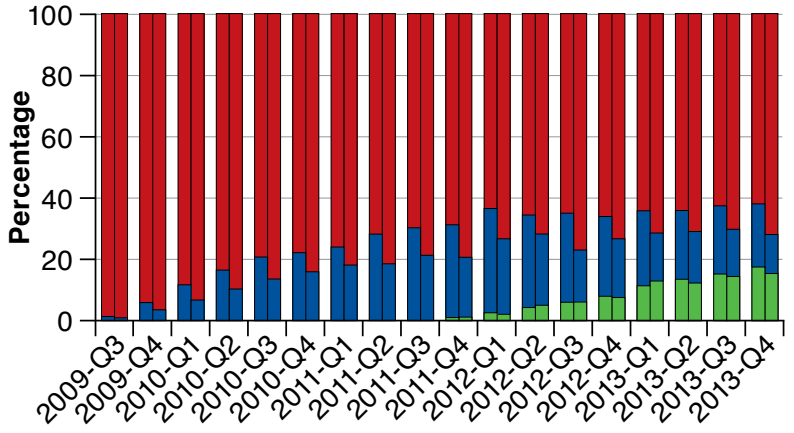

Note: Left columns: male; right columns: female.

\section{B. Trends by Age Group}

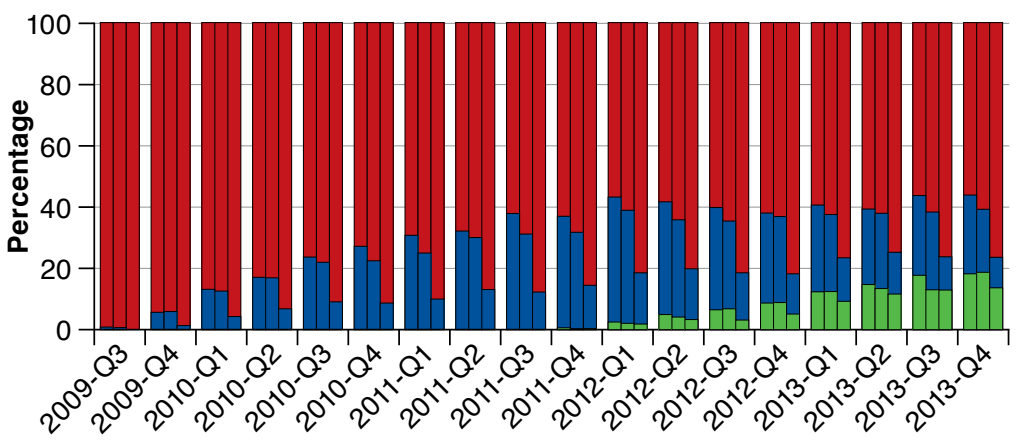

Note: From left to right in each quarter: age < 55 years, $55-64$ years, and 65 years.

\section{Trends by Health Plan}

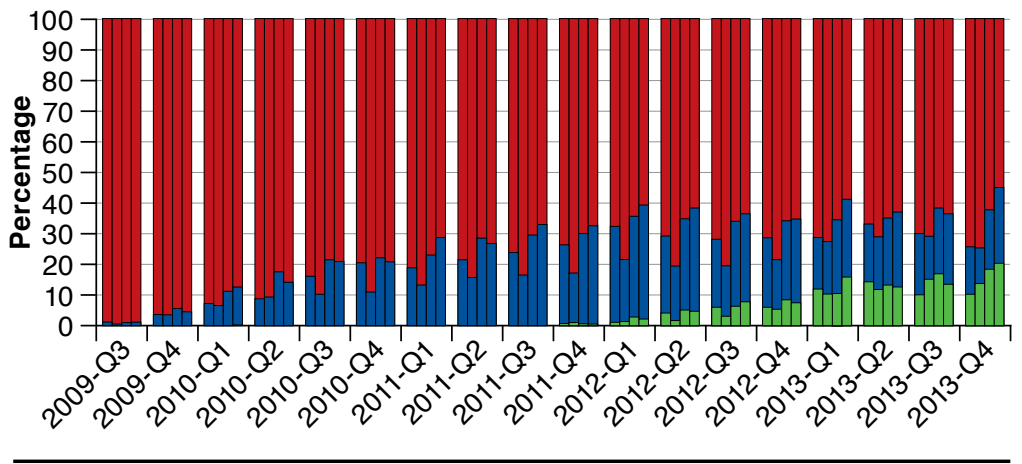

Note: From left to right in each quarter: HMO, comprehensive, $\mathrm{PPO}$, and other health plans. 